Tropical Journal of Pharmaceutical Research June 2010; 9 (3): 293-299

(C) Pharmacotherapy Group,

Faculty of Pharmacy, University of Benin

Benin City, 300001 Nigeria.

All rights reserved.

Research Article

Available online at http://www.tjpr.org

\title{
Formulation of Nimesulide Floating Microparticles Using Low-viscosity Hydroxypropyl Methylcellulose
}

\author{
Shujaat Ali Khan, Mahmood Ahmad, Ghulam Murtaza*, \\ Muhammad Naeem Aamir, Nisar-ur-Rehman, Rozina Kousar, \\ Fatima Rasool and Mohammad Akhtar \\ Faculty of Pharmacy and Alternative Medicine, The Islamia University of Bahawalpur, Bahawalpur-63100, Pakistan.
}

\begin{abstract}
Purpose: To formulate prolonged-release floating microparticles that would minimise the irritant effect of weakly acidic drugs, such as nimesulide, on the stomach by avoiding direct contact with gastric mucosa. Methods: Sustained release floating microparticles of nimesulide was prepared by a coacervation (nonsolvent addition technique. Three different ratios of the coacervating polymer, low-viscosity hydroxypropyl methylcellulose (HPMC), were used, and the dissolution characteristics of the floating microparticles in simulated gastric and intestinal media were evaluated. In order to determine whether there was drug - polymer interaction, the microparticles were also assessed by infra-red (FTIR) spectroscopy and $x$-ray diffraction (XRD). Micromeritic properties of the microparticles were also assessed.

Results: The drug content of the floating microparticles increased with increase in the level of HPMC incorporated. All floating microparticles formulations showed good flow properties while particle size analysis revealed that the appearance and size distribution of the formulations varied with polymer concentration. FTIR and XRD data indicated the crystalline nature of the drug but there was no chemical interaction between the drug and the polymer in the microparticles. Nimesulide release was faster in simulated intestinal fluid ( $\mathrm{pH}$ 6.8) than in simulated gastric fluid ( $\mathrm{pH}$ 1.2) and distilled water ( $\mathrm{pH}$ 6.5).

Conclusion: Coacervation non-solvent addition is a suitable technique for preparing floating microparticles of nimesulide using low-viscosity HPMC.
\end{abstract}

Keywords: Floating microparticles, Nimesulide, HPMC, Coacervation, Non-solvent addition, Sustained release. 


\section{INTRODUCTION}

Nimesulide (4-nitro-2-phenoxymethane-sulfonanilide) is a non-steroidal anti-inflammatory drug (NSAID) that is weakly acidic (pKa 6.5) and differs from other NSAIDs in that its chemical structure contains a sulfonanilide moiety as the acidic group [1]. It has good anti-inflammatory, analgesic and antipyretic activity, and is well tolerated by patients as demonstrated in clinical trials [2]. Nimesulide is the first marketed drug with a selective inhibition of prostaglandin synthesis via cyclooxygenase-2 (COX-2), which results in lower toxicity in the gastrointestinal mucosa and the kidney $[3,4]$.

Microencapsulation is a common technique used in the production of sustained release dosage forms. Microcapsule-based drug delivery systems have received considerable attention in recent years. A number of methods have been devised to prepare microparticles of varying size, shape, as well as release and surface properties [5].

Gastrointestinal transit time is one of the several physiological limitations that must be controlled in the development of per-oral sustained release dosage forms. Various attempts have been made to prolong the retention time of the dosage form in the stomach. One such method is the preparation of a device that remains buoyant in stomach contents due to a density that is lower than that of gastric fluids. On the other hand, a floating system made up of multiple units has relative merits compared to a single unit preparation [6]. Indeed, gastric emptying of a multiparticulate floating system would occur in a consistent manner with small individual variations. On each subsequent gastric emptying, sunken particles will spread out more uniformly over a large area of absorption sites, increasing the opportunity for drug release profile and absorption in a more or less predictable way. Moreover, since each dose consists of many subunits, the risk of dose dumping is reduced $[7,8]$. The concept of floating microparticles can also be utilized to minimize the irritant effect of weakly acidic drugs on the stomach by avoiding direct contact with the mucosa and thus providing a means of making available low dosage for prolonged periods [6].

The objective of the present study was to formulate a suitable gastroretentive floating microparticulate delivery system of a weakly acidic drug, nimesulide, using hydroxypropyl methylcellulose (HPMC) as the gel-forming polymer.

\section{EXPERIMENTAL}

\section{Materials}

Nimesulide BP was donated by Pharm-Evo Pharma (Pvt) Ltd, Karachi, Pakistan while HPMC (viscosity grade, 40 - $60 \mathrm{cps}$ ) was purchased from Sigma, USA. Dichloromethane, liquid paraffin and $n$ hexane, which were of analytical grade, were supplied by Merck Germany.

\section{Preparation of microparticles}

The microparticles were prepared by first dissolving nimesulide $(1 \mathrm{~g})$ and $\operatorname{HPMC}(1,2$ and $3 \mathrm{~g})$ in dichloromethane $(20 \mathrm{ml})$ at room temperature. Liquid paraffin $(50 \mathrm{ml})$ was added slowly to the solution with constant stirring using a magnetic stirrer at a rate of $700 \mathrm{rpm}$ for $2 \mathrm{~h}$. The finely dispersed droplets of the polymer-drug were filtered and washed thrice with n-hexane and dried.

\section{In vitro drug release studies}

In vitro release of nimesulide from microparticles was evaluated in simulated gastric fluid $(0.1 \mathrm{M} \mathrm{HCl}, \mathrm{pH} 1.2)$, distilled water ( $\mathrm{pH}$ 6.5) and simulated intestinal fluid (phosphate buffer, $\mathrm{pH}$ 6.8) separately. An amount of the microparticles, equivalent to $100 \mathrm{mg}$ of nimesulide was transferred to the dissolution medium $\left(900 \mathrm{~mL}, 37{ }^{\circ} \mathrm{C}\right)$ in a USP XXII apparatus (basket method I, Pharma Test, Germany) operating at a speed of 100 rpm. Samples were withdrawn at intervals 
over a period of $10 \mathrm{~h}$ with an automated sample collector after filtering through a 10 $\mu \mathrm{m}$ Sinter filter and replaced immediately with an equal volume of fresh dissolution medium. The samples were analyzed for nimesulide using a UV-VIS spectrophotometer (Shimadzu UV-1601, Japan) at $404 \mathrm{~nm}$ [9]. The results were expressed as mean $( \pm S D)$ of three tests.

\section{Analysis of release data}

The data obtained from the in vitro drug release studies were fitted into various release models, namely, zero order, first order, Higuchi square root, Hixson-Crowell cube root and Korsmeyer-Peppas [17]. Additionally, the similarity factor, $f_{2}$, was used to assess differences in dissolution profiles as in Eq 1 [18].

$f_{2}=50 \log \left\{1+1 / n \sum\left(R_{t}-T_{t}\right)^{2}\right\}^{-0.5} \times 100$

\section{Assessment of micromeritic properties}

The microparticles were characterized for various micromeritic properties. Particle size was measured using an optical microscope (XSZ-150A, Ningbo, China) with the mean particle size calculated by measuring the size of 200 particles with the aid of a calibrated ocular micrometer. The tapping method was used to determine tapped density and compressibility index as in Eqs 2 and 3, respectively [10].

\section{Tapped density $=M / V$}

where $M$ is the mass of the microparticles and $\mathrm{V}$ is the volume of the microparticles after tapping

Compressibility index $(\%)=\left(1-V / V_{0}\right) \times 100 \ldots .(3)$

where $\mathrm{V}$ and $\mathrm{V}_{0}$ are the volumes of the sample after and before tapping, respectively. The true density of the particles was determined using the displacement method with benzene as the displacement liquid. Porosity $(\varepsilon, \%)$ was calculated using Eq 4 [11].
$\varepsilon(\%)=\left(1-P_{p} / P_{t} \times 100\right.$

where $P_{t}$ and $P_{p}$ are the true density and tapped density, respectively. Angle of repose of the microparticles, which measures the resistance to particle flow, was determined by the fixed funnel method and calculated as in Eq 5 [12].

$\theta=\tan ^{-1} h / r$

where $r$ is the radius and $h$ is the height of the microparticle heap. Hausnner's ratio, another index of flowability, was calculated using Eq 6.

Hausner's ratio $=V / V_{0}$

where $\mathrm{V}$ is the volume before tapping and $\mathrm{V}_{0}$ is the volume after tapping. Packing factor was calculated as the ratio of bulk density after tapping to bulk density before tapping, as indicated in Eq 7 [13].

Packing factor $\left(P_{f}\right)=D / D_{0}$

where $D$ is the bulk density after tapping and $D_{0}$ is the bulk density before tapping.

\section{Scanning electron microscopy}

The microparticles were mounted directly onto the sample stub and coated with gold film $(200 \mathrm{~nm})$ and their surface characterized by scanning electron microscopy (Philips-XL20, The Netherlands) under reduced pressure (0.133 $\mathrm{Pa})$.

\section{Wall thickness}

The wall thickness $(h)$ of the microparticles was computed using Eq 8 [14].

$h=r(1-p) d_{1} / 3\left\{p d_{2}+(1-p) d_{1}\right\}$

where $r=$ arithmetic mean radius, $d_{1}=$ density of core material, $\mathrm{d}_{2}=$ density of coat material, and $p=$ proportion of drug in microparticles 


\section{Buoyancy}

Fifty milligrams of the floating microparticles were placed in simulated gastric fluid $(\mathrm{pH} 1.2$, $100 \mathrm{ml}$ ) containing $0.02 \mathrm{w} / \mathrm{v} \%$ Tween 20 and stirred at $100 \mathrm{rpm}$ with a magnetic stirrer. After $8 \mathrm{~h}$, the layer of buoyant microparticles was pipetted and separated by filtration. The sunken particles were also separated by filtration. Both sets of particles were dried in a desiccators over silica gel for $24 \mathrm{~h}$ to constant weight and the weight noted. Buoyancy was determined as in Eq 9 [15].

$$
\text { Buoyancy }(\%)=W f /(W f+W s) \times 100 \ldots .
$$

Where Wf and Ws are the weights of the floating and settled microparticles, respectively. All the determinations were made in triplicate.

\section{Determination of drug entrapment efficiency, drug loading and yield}

Accurately weighed $25 \mathrm{mg}$ microparticles were suspended in $25 \mathrm{ml}$ of methanol. After $24 \mathrm{~h}$, the solution was filtered and the filtrate analysed for drug content spectrophotometrically at $404 \mathrm{~nm}$. Drug entrapment efficiency (EE) was determined using Eq 10:

$$
E E(\%)=A / T \times 100
$$

where $\mathrm{A}=$ actual drug content and $\mathrm{T}$ =theoretical drug content. Yield was calculated as in Eq 11.

Yield $(\%)=P /\left(W_{D}+W_{P}\right) \times 100$

where $P$ is the weight of the microparticles, and $W_{D}$ and $W_{P}$ are the weights of drug and polymer, respectively, used in forming the microparticles. Each determination was performed in triplicate [16].

\section{Compatibility test}

Diffractograms of the drug, HPMC and floating microparticles were obtained using a
Philips PW 1830 X-ray diffractometer. The radiation source was a copper $(\lambda=1.54184 \AA)$ high-intensity $\mathrm{x}$-ray tube operated at $35 \mathrm{KV}$ and $15 \mathrm{~mA}$. Fourier transform infrared spectroscopy (Shimadzu, FTIR-8400) was conducted on the materials to determine if there was any interaction between the drug and the polymer; they were scanned in the IR range of 500 to $4000 \mathrm{~cm}^{-1}$ by $\mathrm{KBr}$ method. The detector was purged carefully with clean dry helium gas to increase signal level and reduce moisture.

\section{Statistical analysis}

Pair-wise procedure, i.e., similarity factor $\left(\mathrm{f}_{2}\right)$ was applied to the release data. One-way ANOVA for significance at $P<0.05$ was conducted for the release profiles using SPSS version 12.0.

\section{RESULTS}

\section{Physicochemical properties of microparticles}

The physicochemical properties of the microparticles are shown in Fig. 1 and Table 1. The SEM photograph (Fig 1) show that the microparticles were spherical with a smooth surface and exhibited a range of sizes within each batch.

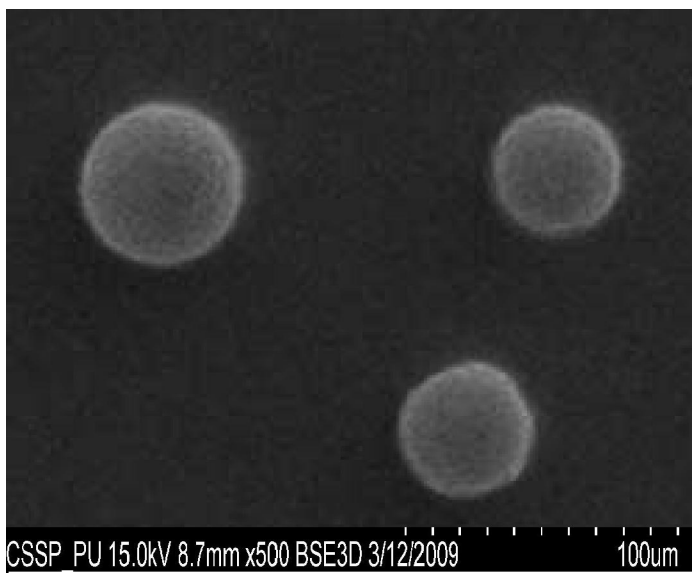

Fig 1: Scanning electron photomicrograph of microparticles 
Yield was in the range 78.5 to $87.1 \%$ while drug entrapment or loading was in the range 66.4 to $81.6 \%$. The microparticles floated for a prolonged time on the surface of the dissolution medium with a buoyancy of 63.4 to $67.7 \%$ after $12 \mathrm{~h}$ and had a wall thickness of $15.6-17.7 \mu \mathrm{m}$.

Table 1: Physicochemical characteristics of microparticle formulations (Mean, $n=3$ )

\begin{tabular}{|c|c|c|c|}
\hline Parameter & M1 & M2 & M3 \\
\hline $\begin{array}{l}\text { Theoretical } \\
\text { loading (\%) }\end{array}$ & 50 & 33.33 & 25 \\
\hline $\begin{array}{l}\text { Actual loading } \\
(\%)\end{array}$ & 35.82 & 27.34 & 19.86 \\
\hline $\begin{array}{l}\text { Encapsulation } \\
\text { efficiency (\%) }\end{array}$ & 66.4 & 79.3 & 81.6 \\
\hline Yield (\%) & 78.5 & 85.3 & 87.1 \\
\hline Buoyancy (\%) & 67.7 & 65.8 & 63.4 \\
\hline Wall thickness & 15.6 & 17.1 & 17.7 \\
\hline Porosity \% & 74.4 & 72.7 & 68.0 \\
\hline $\begin{array}{l}\text { Angle of } \\
\text { repose }\end{array}$ & $19.6 \pm 0.5$ & $20.3 \pm 0.6$ & $23.7 \pm 0.6$ \\
\hline $\begin{array}{l}\text { True Density } \\
\left(\mathrm{g} / \mathrm{cm}^{3}\right)\end{array}$ & $\begin{array}{l}0.165 \pm \\
0.014\end{array}$ & $\begin{array}{l}0.216 \pm \\
0.013\end{array}$ & $\begin{array}{l}0.241 \pm \\
0.017\end{array}$ \\
\hline $\begin{array}{l}\text { Tapped } \\
\text { density }\left(\mathrm{g} / \mathrm{cm}^{3}\right)\end{array}$ & $\begin{array}{l}0.229 \pm \\
0.025\end{array}$ & $\begin{array}{l}0.283 \pm \\
0.131\end{array}$ & $\begin{array}{l}0.309 \pm \\
0.142\end{array}$ \\
\hline $\begin{array}{l}\text { Compressibility } \\
\text { index }\end{array}$ & $28.0 \pm 0.2$ & $24.0 \pm 0.17$ & $22.0 \pm 0.16$ \\
\hline $\begin{array}{l}\text { Hauser' ratio } \\
\text { Packing factor }\end{array}$ & $\begin{array}{l}1.14 \pm 0.51 \\
1.38 \pm 0.25\end{array}$ & $\begin{array}{l}1.32 \pm 0.25 \\
1.31 \pm 0.16\end{array}$ & $\begin{array}{l}1.28 \pm 0.25 \\
1.28 \pm 0.36\end{array}$ \\
\hline $\begin{array}{l}\text { Mean particle } \\
\text { size }(\mu \mathrm{m})\end{array}$ & $116.6 \pm 27.7$ & $128.4 \pm 29.5$ & $132.8 \pm 28.7$ \\
\hline
\end{tabular}

Tapped density ranged from 0.229 to 0.309 $\mathrm{g} / \mathrm{cm}^{3}$, while true density was between 0.165 and $0.241 \mathrm{~g} / \mathrm{cm}^{3}$ for all the formulations, the fairly wide range being due, probably, to the presence of fractions of low-density particles within the microparticles. Microparticle porosity was in the range of $68.0-74.4 \%$ while compressibility index ranged from 22.0 to $28.0 \%$. All the formulations showed excellent flowability, judging by their angle of repose which was between $19.6 \pm 0.5$ and $23.7 \pm 0.6^{0}$, thus indicating that the microparticles were non-aggregated. Their size ranged from 116.6 to $132.8 \mu \mathrm{m}$.

Fig 2 and Table 2 show the release data for the microparticles. The release rate of drug from formulation $M 1$ was comparatively higher than that from $\mathrm{M} 2$ and $\mathrm{M} 3$ but this difference in drug release behaviour was non-significant $(p>0.05)$. The lower the concentration of the polymer (HPMC), the faster the release of drug from the microparticles. Moreover, the drug release characteristics from all formulations fitted best to Higuchi kinetic model as evident from its higher value of regression coefficient (Table 2).

Table 2: Drug release kinetics of the microparticle formulations (nean, $n=3$ )

\begin{tabular}{cccc}
\hline Model & \multicolumn{3}{c}{ Regression coefficient } \\
& \multicolumn{3}{c}{$\mathbf{R}^{2}$ ) } \\
\cline { 2 - 4 } & \multicolumn{1}{c}{$\mathbf{M 1}$} & $\mathbf{M}$ & $\mathbf{M}$ \\
\hline $1^{\text {st }}$ order & 0.8996 & 0.8957 & 0.9257 \\
$2^{\text {nd }}$ order & 0.4293 & 0.4234 & 0.5322 \\
Higuchi & 0.9955 & 0.9958 & 0.9821 \\
Hixson & 0.9702 & 0.9815 & 0.9734 \\
Korsemeyer- & 0.9980 & 0.9947 & 0.9959 \\
Peppas & $(0.5)$ & $(0.5)$ & $(0.7)$ \\
\hline
\end{tabular}

Data in parenthesis represent KorsemeyerPeppas release exponent, $n$.
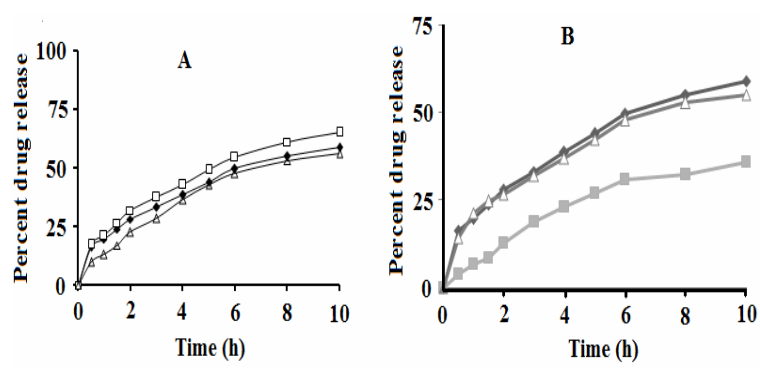

Fig 2: Release profiles of $(A)$ various microparticle formulations ( $\square=M 1 ;=M 2 ; \boldsymbol{\Delta}=M 3$ ) in phosphate buffer ( $\mathrm{pH} 6.8)$; and (B) formulation $\mathrm{M} 1$ in various dissolution media $(=0.1 \mathrm{M} \mathrm{HCl}, \mathrm{pH} 1.2$; $-=$ phosphate buffer, $\mathrm{pH} 6.8 ; \boldsymbol{\Delta}=$ distilled water, $\mathrm{pH}$ 6.5)

\section{Drug-polymer compatibility}

In order to determine the physical state of the drug in the microparticles, especially possible drug/polymer interaction, x-ray diffraction was conducted for the pure drug, the polymer and 
the microparticles. The results are shown in Figure 3 . The $x$-ray diffraction patterns indicate that the pure drug exhibited crystalline characteristics, while polymer diffractogram showed an amorphous pattern. The peaks are denser in the microparticle formulation due, probably, to re-crystallization of the drug on the surface of microparticles.

The FTIR spectra of the drug (see Figure 3) indicate the presence of bands at $906-640$ $\mathrm{cm}^{-1}$ (C-H aromatic), $1078 \mathrm{~cm}^{-1}$ ( $\left.\mathrm{S}=\mathrm{O}\right), 1159$ $\mathrm{cm}^{-1}$ (C-O-C ether linkage), $1077 \mathrm{~cm}^{-1}\left(\mathrm{CH}_{3}\right.$ $\mathrm{C}-\mathrm{H}$ bending), 1516 and $1340 \mathrm{~cm}^{-1}\left(\mathrm{NO}_{2}\right)$ and $3286 \mathrm{~cm}^{-1}(\mathrm{~N}-\mathrm{H})$. The spectra of the microparticles also showed essentially identical peaks at the same bands, thus indicating that there was no chemical interaction between nimesulide and HPMC in the microparticles.
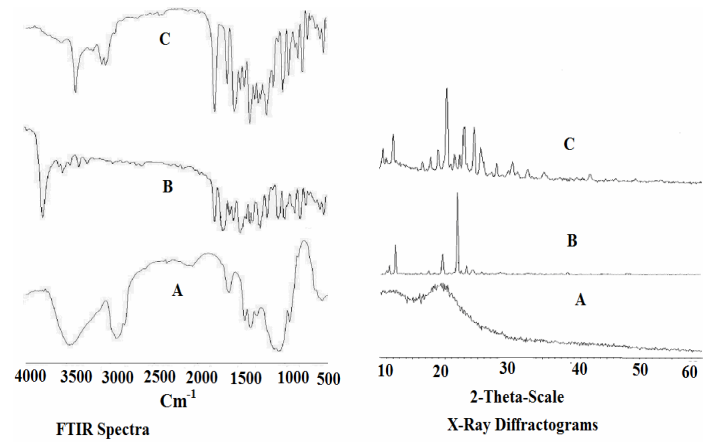

Fig 3: FTIR spectra and $x$-ray diffratograms of $(A)$ HPMC, (B) pure nimesulide, and (C) microparticles (M1)

\section{DISCUSSION}

Microencapsulation of nimesulide with HPMC produced microparticles with good flow characteristics. Entrapment efficiency and other physicochemical properties were similar to those previously reported for other microparticles [6]. Cumulative release of nimesulide decreased significantly with increasing HPMC concentration (Figure 2). However, f2 values of the dissolution profiles were between 50 and 70 which indicate similarity of the dissolution data for various formulations. Increase in polymer concentration from 1:1 to 1:3 (drug:polymer) also increased yield, entrapment efficiency, buoyancy, wall thickness and microparticle size $[19,20]$. There was increase $(p>0.05)$ in particle size and wall thickness with increase in polymer concentration and this may be attributed to increased aggregation of the polymer particles as its concentration increased. With increasing polymer content, more particles of nimesulide would be coated leading to higher encapsulation efficiency $[27,28]$. However, this increase was nonsignificant $(p>0.05)$.

On fitting the data into release models (zeroorder, first-order, Higuchi, Hixson-Crowell and Korsmeyer-Peppas), the highest regression coefficient values were found for the Higuchi model, indicating that diffusion was the predominant mechanism of drug release. The data derived from the HixsonCrowell model indicate a change in the surface area and diameter of the particles with progressive dissolution of the matrix as a function of time while the plot for the Korsmeyer-Peppas model showed good linearity. The release exponent, $\mathrm{n}$, was in the order $0.45<\mathrm{n}<0.89$, which appears to indicate a coupling of diffusion and erosion mechanisms, i.e., the so-called anomalous diffusion, and this probably indicates that drug release was controlled by more than one process (see Table 1). Release data for formulation $\mathrm{M} 1$ in phosphate buffer $(\mathrm{pH} \mathrm{6.8)}$, $0.1 \mathrm{M} \mathrm{HCl}(\mathrm{pH} 1.2)$ and distilled water $(\mathrm{pH} 6.5)$ showed that $58.9,35.8$ and $55.0 \%$ of nimesulide, respectively, were released after $10 \mathrm{~h}$. This is due to the fact that acidic drugs ionize/dissolve more in a basic medium than in an acidic one.

\section{CONCLUSION}

Nimesulide microparticles of varying size and drug content can be obtained, using a coacervation non-solvent addition technique, by varying low-viscosity HPMC content. With the microparticles of nimesulide showing excellent floatability, good buoyancy and 
prolonged drug release (based mainly on diffusion-controlled mechanism) and absence of chemical interaction between drug and polymer, it can be stated that the floating microparticles constitute a potential candidate for multiple-unit delivery devices for intragastric drug absorption.

\section{REFERENCES}

1. Magni E. Nimesulide- an overview. Drug Invest. 1991; 2: 1-3.

2. Marini U, Spotti D, Magni E, Monti T. Double blind endoscopic study comparing the effect of Nimesulide and placebo on gastric mucosa of dyspeptic subjects. Drug Invest. 1990; 2: 162166.

3. Garcia-Nieto $R$, Perez $C$, Checa $A$, Gago $F$. Molecular model of the interaction $b / w$ Nimesulide and human cycloxygynase-2. Rheumatol. 1999; 38: 14-18.

4. Bennett A, VILLA G. Nimesulide: an NSAIDS that preferentially inhibits COX-2, and has various unique pharmacological effects. Exp. Opinion Pharmacotherap. 2000; 1:277-286.

5. Jain NK. Controlled and Novel Drug Delivery. $1^{\text {st }}$ Ed. New Delhi: CBS Publishers and Distributors, 1997, 526-555.

6. Soppimath KS, Kulkarni AR, Rudzinski WE, Aminabhavi TM. Microspheres as floating drug-delivery systems to increase gastric retention of drugs. Drug Metabol. Rev. 2002; 33: 149-160.

7. Muthusamy K, Govindarazan G, Ravi TK. Preparation and evaluation of lansoprazole floating micropellets. Ind. J Pharm. Sci. 2005; 67: 75-79.

8. Joseph NJ, Lakshmi S, Jayakrishnan A. A floatingtype oral dosage form for piroxicam based on hollow polycarbonate microspheres: in vitro and in vivo evaluation in rabbits. J. Control. Release 2002; 79: 71-79.

9. Indian Pharmacopoeia, $3^{\text {rd }}$ Ed. Delhi: Controller of publications, 1996, vol. II, p A7.

10. Shariff A, Manna PK, Paranjothy KLK, Manjula M. Entrapment of andrographolide in cross-linked alginate pellets: II. Physicochemical characterization to study the pelletization of andrographolide. Pak. J. Pharm. Sci. 2007; 20: $1-9$.

11. Nana Li, Xiao C. Preparation and properties of UHMWPE/SiO2 hybrid hollow fibre membranes via thermally induced phase separation-stretching method. Iranian Polymer J. 2009; 18: 479-489

12. Dashora K, Saraf S, Saraf S. In-vitro studies of tizanidine controlled release microcapsullar matrices. Pak. J. Pharm. Sci. 2006; 19: 177181.

13. Ritschel WA, Thompson GA, Lucker PW, Wetzelsberger K. Biopharmaceutic evaluation of etofylline clofibrate and its drug formulation. Drug Res. 1980; 30: 2020-2023.

14. Chowdary KPR, Koteshwara R. Ethyl cellulose microsphere of Glipizide: Characterization in vitro and in vivo evaluation. Ind. J. Pharm. Sci. 2004; 66: 412-416.

15. Jain SK, Awasthi AM, Jain NK, Agrawal GP. Calcium silicate based microsphere of ripaglinide for gastroretentive floating drug delivery: preparation and in vitro characterization. J. Control. Release 2005; 107: 300-309.

16. Murtaza G, Ahmed M, Akhtar N. A Comperative study of various microcapsulation technique: Effect of polymer viscosity on microcapsule characterstics. Pak. J. Pharm. Sci. 2009; 22: 291-300.

17. Laware RB, Nirmal SA, Joshi SV. Preparation and evaluation of controlled release microcapsules of diclofenac sodium. Ind. Drugs 2008; 45: 279-287.

18. Moore JW, Flanner HH. Mathematical comparison of dissolution profiles. Pharm. Technol. 1996; 20: 64-74.

19. Michael C, Ilia-Fishbein MD, Haim DD, Gershon G. Lipophilic drug nanospheres prepared by nanoprecipitaion: effect of formulation variables on size, drug recovery and release kinetics. J. Control. Release 2002; 83: 389400.

20. Youan BBC, Jacson TL, Dickens L, Hernandez C, Ababio GO. Protein release profiles and morphology of biodegradable microcapsules containing an oily core. J. Control. Release 2001; 76: 313-326. 